\title{
Approaches on the Major Predictors of Blood Transfusion in Cardiovascular Surgery: A Systematic Review
}

\author{
Maria Christiane Valéria Braga Braile-Sternieri', Eliana Migliorini Mustafa1, \\ Victor Rodrigues Ribeiro Ferreira',2, Sofia Braile Sabino', Cibele Olegário Vianna Queiroz', \\ Bethina Canaroli Sbardellini', Giovanni Braile Sternieri' ${ }^{1}$, Lúcia Angélica Buffulin de Faria ${ }^{1}$, \\ Idiberto José Zotarelli Filho ${ }^{*}$, Domingo Marcolino Braile ${ }^{1}$
}

\author{
${ }^{1}$ Domingo Braile Institute of Sao Jose do Rio Preto (SP), Rua Luiz Vaz de Camoes, Sao Jose do Rio Preto, Sao Paulo, Brazil \\ ${ }^{2}$ Faceres, Medical School of Sao Jose do Rio Preto, Sao Jose do Rio Preto, Sao Paulo, Brazil \\ Email: *scientific@institutodomingobraile.com.br, m.zotarelli@gmail.com
}

How to cite this paper: Braile-Sternieri, M.C.V., Mustafa, E.M., Ferreira, V.R.R., Sabino, S.B., Vianna Queiroz, C.O., Sbardellini, B.C., Sternieri, G.B., Buffulin de Faria, L.A., Zotarelli Filho, I.J. and Braile, D.M. (2019) Approaches on the Major Predictors of Blood Transfusion in Cardiovascular Surgery: A Systematic Review. Health, 11, 371-379.

https://doi.org/10.4236/health.2019.114033

Received: February 14, 2019

Accepted: April 15, 2019

Published: April 18, 2019

Copyright () 2019 by author(s) and Scientific Research Publishing Inc. This work is licensed under the Creative Commons Attribution International License (CC BY 4.0).

http://creativecommons.org/licenses/by/4.0/

\begin{abstract}
Introduction: Experimental Clinical studies have shown that loss of up to $77.0 \%$ of red cell mass can be tolerated as long as it kept the blood volume. However, the blood volume loss of about $34.0 \%$ is fatal. The initial attention in patients with bleeding should be given to maintaining blood volume and oxygen transport. Thus, transfusions of allogeneic blood products are associated with an increased risk of morbidity and mortality in cardiac surgery. Some transfusion risk scores have been proposed for cardiac surgery patients. Objective: To review and discuss literature blood transfusion (blood components gradient) in cardiovascular surgery versus polytrauma, gastrointestinal bleeding, and neoplastic diseases. Methods: The model followed for the review was PRISMA. We used the databases as Scielo, Lilacs, Google Scholar, PubMed articles and works of scientific and doctoral theses master. Results: According to the discussion in the literature, the acute bleeding of large volumes is challenging to emergency services. Accordingly, the need to support hemotherapeutics led to the development of protocols for more rational utilization of the monitored blood components. Conclusion: Hemotherapy services have adopted a very dynamic approach to the clinical condition presented by patients, the need for four or more red blood cell units.
\end{abstract}

\section{Keywords}

Cardiovascular Surgery, Polytrauma, Transfusion Blood Components, Survival, Epidemiologic Data, Time to Hemostasis, Derivatives Volume 


\section{Introduction}

In the United States, the trauma is a major cause of death among people 1 - 44 years and the third leading cause of death among others. Approximately $21.0 \%$ to $44.0 \%$ of trauma deaths or cardiovascular surgery occurs after admission and result from massive hemorrhage [1] [2]. There are multicenter studies or randomized clinical corroborating with the practice of resuscitation with blood products, so there are many conflicting recommendations [2].

Transfusion of allogeneic blood products is associated with an increased risk of morbidity and mortality in cardiac surgery. Currently, some transfusion risk scores have been proposed for cardiac surgery patients. In other Western countries, it is the third cause of death after cardiovascular diseases and cancers, and those below 45 years of age, the leading cause of death [3]. According to the Ministry of Health, there were 127,633 deaths from trauma in Brazil in 2005, representing $12.67 \%$ of total deaths. In December 2015, there were 86,583 hospitalizations for trauma in the country [3].

In addition, PRP before cardiopulmonary bypass (CPB) and transfusion of autologous platelet-rich plasma (aPRP) after reversal of heparin could reduce postoperative blood loss. Experimental clinical studies have shown that the loss of up to $75.0 \%$ of red cell mass can be tolerated as long as the blood volume remains. However, the blood volume loss of about $30.0 \%$ is fatal [4] [5]. The initial attention in patients with bleeding should be given to maintaining blood volume, and we should then stick to the oxygen-carrying capacity. The patient should be clinically evaluated in order to quantify blood loss, which is often difficult for a patient with bleeding. Therefore, it is recommended by the ATLS (Advanced Trauma Life Support) [5] [6] [7].

In general, there is no need for red blood cell transfusion for patients with acute trauma of Class I and II, particularly in young patients who can adapt well to anemia due to acute loss, and should receive crystalloid solutions [8]. If more than $40 \%$ of the blood volume has been lost (Class III and IV) in young patients or less in elderly patients who may already have critically impaired physiological functions in addition to receiving crystalloid solutions, it needs to restore the ability of oxygen delivery, and reversible replacement elements responsible for homeostasis [8].

The prospective observational multicenter study of transfusion in trauma (The Prospective Observational Multicenter Major Trauma Transfusion Trial) showed that doctors were transfusing patients with blood products in a 1:1:1 or 1:1:2 relative to plasma, platelets and red blood cells [9]. It was also demonstrated that early plasma and platelet transfusion associated with improvement in survival at 6 hours after admission (Holcomb). In patients with severe trauma, and severe hemorrhage, the early administration of plasma, platelets and CHAD in the ratio 1:1:1 compared to a ratio of 1:1:2 resulted in no significant differences in mortality at 24 hours and mortality 30 days, however, more patients in group 1:1:1 obtained homeostasis and lower mortality due to exsanguination in 
$24 \mathrm{~h}$. Although there was an increase in the use of plasma and platelets transfused group 1:1:1, no other significant differences identified between the two groups [9].

This study aimed to make a literary discussion of blood transfusion (blood components gradient) in patients under cardiovascular disease, correlating the statistical data of the main continuous and categorical predictors the polytrauma, gastrointestinal disease and neoplastic diseases with the main predictors of response, fluid replacement.

\section{Methods}

The model followed for the review was PRISMA

(http://www.prisma-statement.org/). We used the databases as Scielo, Lilacs, Google Scholar, PubMed articles and works of scientific and doctoral theses master, according to Flow Chart below. The main descriptors (Mesh Terms) used were "Cardiovascular surgery", "Polytrauma", "Transfusion Blood components", "Survival", "Epidemiological data", "Time to hemostasis", "Volume-based", as shown by Figure 1 and Figure 2 .

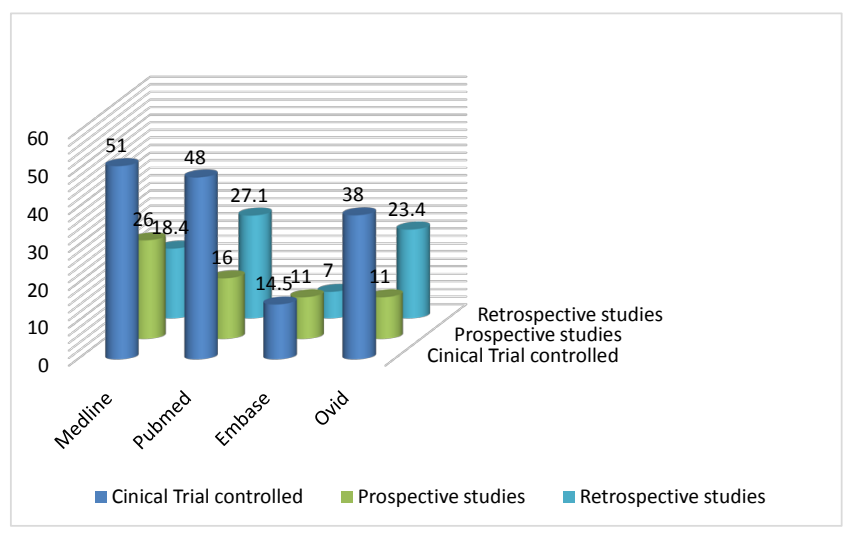

Figure 1. Graph showing the distribution of literature findings in databases on blood transfusion in cardiovascular surgery.

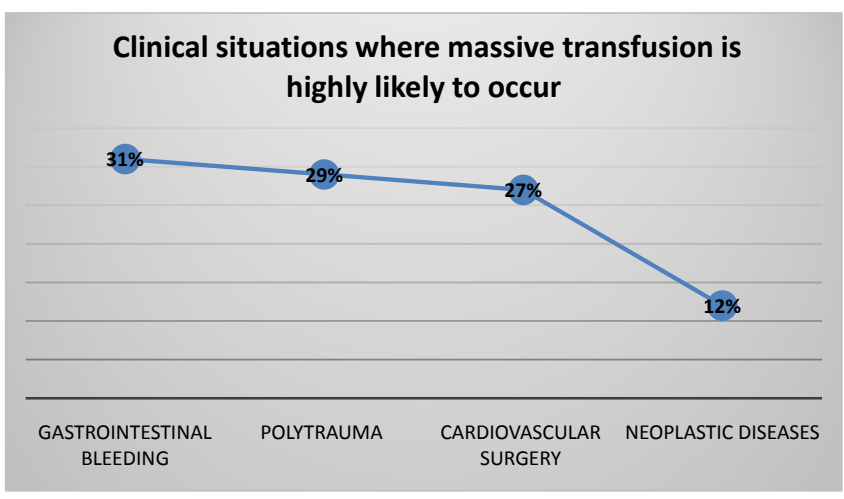

Figure 2. Graph representing the demand for blood transfusion percentage of mass in relation to cardiovascular surgery versus gastrointestinal bleeding, polytrauma and neoplastic disease. 


\subsection{Flow Chart}

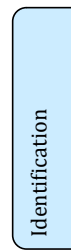

Records identified through database searching $(n=38)$
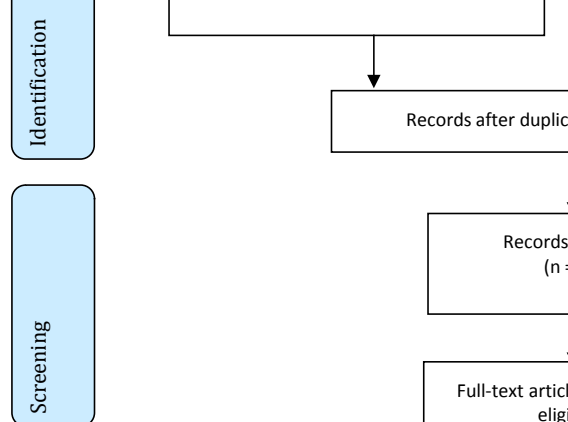

Additional records identified through other sources $(n=10)$

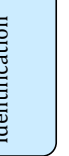

sources $(n=10)$

Records after duplicates removed $(n=48)$
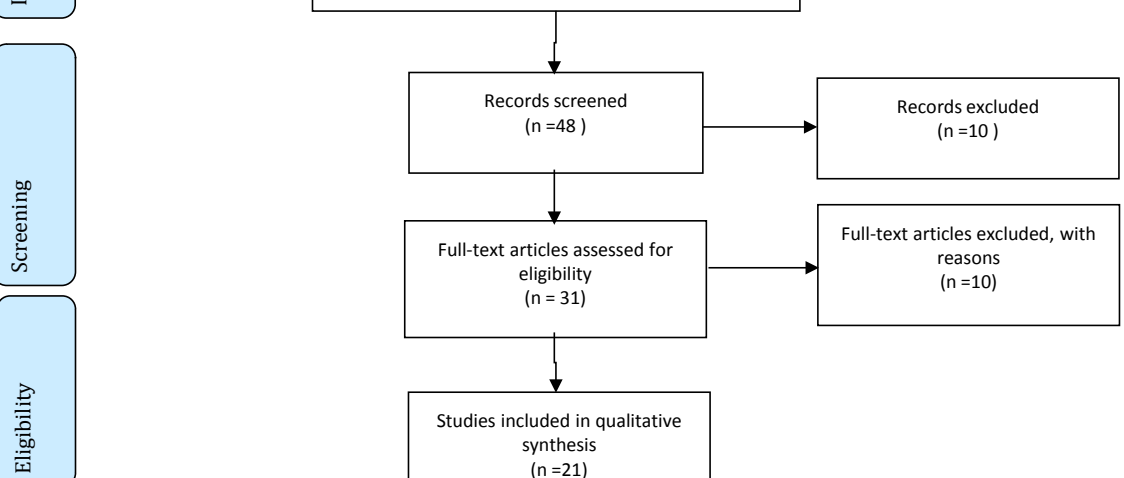

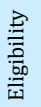

tudies included in qualitative synthesis $(n=21)$
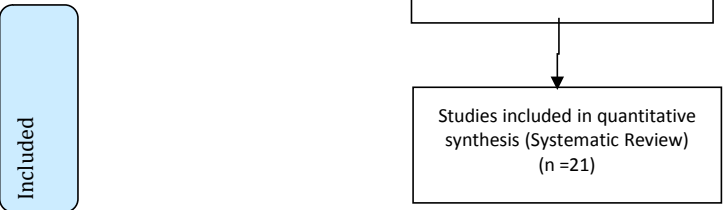

\subsection{Continuous Predictors}

The continuous predictors were cardiovascular surgery, polytrauma, gastrointestinal bleeding and neoplastic diseases.

\subsection{Response Predictors}

The response predictors were "Volume replacement", "Time to hemostasis" and "Survival".

\subsection{Primary Outcome}

It was to assess the efficacy and safety of blood products in transfusions in patients with severe cardiovascular surgery, severe trauma and severe bleeding using plasma, platelets and red blood cells $(\mathrm{CH})$.

\subsection{Secondary Outcome}

To analyze the quality of life after transfusion of blood products.

\section{Literature Review and Discussion}

According to the literature, it was found several works and among them were highlighted the following in sequence, with a focus on blood transfusion (blood components gradient) in patients under cardiovascular surgery, polytrauma, gastrointestinal bleeding and neoplastic diseases.

In this context, one study evaluated the use of atorvastatin in relation to bleeding after cardiac surgery. Thus, they observed that postoperative bleeding 
was significantly lower in the atorvastatin group compared to controls in the first 12 hours after surgery ( $372 \pm 137$ vs $561 \pm 219 \mathrm{ml}$; $\mathrm{p}=0.001)$ and considering overall bleeding $(678 \pm 387$ vs $981 \pm 345 \mathrm{ml}, \mathrm{p}=0.001)$. A total of $32.3 \%$ of controls and $26.3 \%$ of atorvastatin users received red blood cell concentrate $(\mathrm{p}=$ 0.027), and major surgical complications were similar between groups. Postoperative time was lower in the atorvastatin group with a mean reduction of 1 day of hospitalization $(6.0 \pm 1.4$ vs $6.9 \pm 2.1$ days, $\mathrm{p}=0.001)$. Postoperative hemorrhage among patients treated with atorvastatin was significantly higher in those who took lower doses compared to those taking higher doses of atorvastatin with a $20 \%$ difference between groups $(p=0.001)$. Preoperative treatment with atorvastatin may reduce postoperative bleeding and transfusion of packed red blood cells in patients undergoing elective isolated aortic valve replacement. This result can translate into a faster recovery after surgery and reduce hospitalization costs [1].

A randomized clinical study on cardiovascular surgery explored the effects of platelet-rich plasmapheresis (PRP) on the amount of postoperative blood loss and the requirements for allogeneic fresh frozen plasma (FFP) and red blood cell (RBC) transfusions. A bibliographic search of 7 online databases was performed. Fifteen randomized controlled trials enrolled a total of 1002 patients, including 501 patients who received PRP and 501 control patients. Meta-analysis of the data from these trials showed that PRP reduced the total volume of postoperative blood loss (standardized mean difference [SMD], -0.74 ; 95\% confidence interval $[\mathrm{CI}],-1.18$ to $-0, \mathrm{P}<0.05)$, reduced postoperative fresh frozen plasma (PFM) (SMD, $-0.38,95 \% \mathrm{CI},-0.69$ to $-0.08, \mathrm{P}<0.05$ ), reduced postoperative red blood cell transfusion (SMD, $-0.44,95 \% \mathrm{CI},-0.77$ to $-0.10, \mathrm{P}<0.05$ ), and reduced the proportion of patients receiving red blood cell transfusions (relative risk [RR], 0.44, 95\% CI, $0.21-0.91, \mathrm{P}<0.05)$ during cardiovascular surgery. PRP before cardiopulmonary bypass $(\mathrm{CPB})$ and transfusion of autologous platelet-rich plasma (aPRP) after heparin reversal could reduce blood loss in the postoperative period, the requirements for transfusion of blood products during cardiovascular surgery [2]. In this sense, transfusions of allogeneic blood products are associated with an increased risk of morbidity and mortality in cardiac surgery. Currently, some transfusion risk scores have been proposed for cardiac surgery patients [2].

Thus, one study developed a new score and compared it with preexisting scores-transfusion risk score and clinical knowledge (TRACK) and TRUST score (Scoring Understanding Scoring Tool) [3]. A total of 1014 adult patients undergoing cardiac surgery were included in the retrospective study. A predictive score was developed from six variables using logistic regression analysis, and the new score was compared with the other existing scores-TRACK and TRUST. The new score had the following predictive factors: age $>58$ years, weight $<63$ $\mathrm{kg}$ for males and $<49 \mathrm{~kg}$ for females, sex (female), complex surgery, hemoglobin $<13.5 \mathrm{~g} / \mathrm{dl}$ and creatinine $>1.36 \mathrm{mg} / \mathrm{dl}$. The validation of the new score demonstrated an acceptable predictive power (area under the curve [AUC] 0.749) and a 
good calibration in the Hosmer-Lemeshow test. The new score was comparable to the TRACK score with $\mathrm{P}=0.578$ (AUC of TRACK 0.756 and AUC of the new score 0.749 ). There was a significant difference between the new score and the TRUST score, $\mathrm{p}=0.01$ (AUC of TRUST 0.72 and AUC of the new score 0.749). The new score is a simple risk model based on six predictors with similar accuracy and calibration in predicting the rate of transfusion in cardiac surgery when compared to the TRACK score [3].

In this context, the transfusion is not without risk, including transfusion reaction, infection, and increased mortality [4]. A hemoglobin level of $7.0 \mathrm{gdL}^{-1}$ is safe in the setting of critical illness, sepsis, gastrointestinal bleeding, and trauma. The doctor should assess and transfuse based on the clinical setting and hemodynamic status of the patient instead of using a specific limit [5] [6].

Another study showed that the ready-made fibrinogen prevented fibrinogen to treat patients with trauma as the first-line treatment of trauma bleeding will increase clot strength, as measured by thrombelastography, transfusion requirements and survival in patients receiving hemostatic resuscitation according to the current standard of care [7].

In addition, another study showed that the importance of red blood cell transfusions may lead to secondary hemochromatosis. Thus, a case was presented describing the acute development of secondary hemochromatosis multiple transfusions in a burned patient. Therefore, the secondary hemochromatosis was unavoidable [8]. Based on other work, it was shown that most polytrauma geriatric patients with severe pelvic fractures were at high risk of massive transfusion [8] [9] [10].

A systematic review study found that components mimic whole blood can produce survival benefits in massively transfused patients after trauma. Twenty-one studies were included in the analysis. Those who received high-experienced rates had a higher survival benefit. [10]. A transfusion study in 24 patients with acute bleeding consisted of an average of 16 to 18 units of red blood cells resuspended (ranging from $4.880 \mathrm{~mL}$ to $5.220 \mathrm{~mL}$ ), fresh frozen plasma ( $980 \mathrm{~mL}$ to $1220 \mathrm{~mL}$ ); cryoprecipitate (average 10 to 15 units or 500 to $750 \mathrm{~mL}$ ) and concentrated platelets (approximately an average of 8 to 12 units ie, $240-360 \mathrm{~mL}$ ). As a result, it was confirmed pathophysiological mechanism in the medical literature that after the transfusion of large volumes of concentrated red cells, develops dilutional coagulopathy, caused by a sharp drop in the platelet count and reduced activity of labile coagulation factors the circulation of the patient [11].

According to the discussion in the literature, the acute bleeding of large volumes is challenging to emergency services [12]. In the historical context, the need to understand the pathophysiology of hemorrhagic shock and the adoption of appropriate therapy dates back to World War I, although significant progress has only been made from the use of plasma volume expander as in World War II. In the '50s, the Korean conflict, and in the 60s and 70s, the Vietnam War, 
brought to American surgeons greater knowledge and experience of hemorrhagic shock [12].

Accordingly, the need to support hemotherapeutic led to the development of protocols for more rational utilization of the monitored blood products [13] [14] [15] [16]. In shock by massive blood loss commitment of both tissue perfusion and oxygenation is critical, as well as complications from the base frame (shock and tissue hypoxia) and secondary to therapy [17] [18] [19].

Thus, when there is massive bleeding in an emergency room or an operating room is necessary to make massive transfusion with replacement of at least one blood volume in a range of up to 24 hours, or to spare $50.0 \%$ of volume in three hours or transfusion of more than 20 units of red blood cells [20] [21].

It is important to remember that only the third volume of crystalloid volume remains in the intravascular space, the rest spills rapidly into the interstitial space, so blood loss, when restored with crystalloid, should maintain the proportion of three volumes of crystalloid for each volume of blood loss [22] [23].

Another detail periods tissue hypoperfusion variables determine significant changes in permeability of microcirculation, causing the distribution to the interstitial space is facilitated, that is alleviated by solutions that increase intravascular colloid osmotic pressure using human albumin solutions or plasma expanders, the use of these is not without complications as interference in hemostasis and anaphylactic reactions [24]. Hematocrit is not a good parameter to guide the decision to transfuse or not to transfuse, due to the fact that it only starts to decrease one to two hours after the onset of hemorrhage [25].

\section{Conclusion}

Therefore, transfusion services have adopted a very dynamic vision to forecast the clinical condition presented by patients, the need for four or more red blood cell units. For more complete service of massive transfusions, it is imperative to review the concepts of volume/perfusion and tissue oxygenation, and the difference that exists between the concepts.

\section{Acknowledgements}

The work was supported by Domingo Braile Institute-São José do Rio Preto-SP, Brazil.

\section{Conflicts of Interest}

The authors declare no conflicts of interest regarding the publication of this paper.

\section{References}

[1] Nenna, A., Spadaccio, C., Lusini, M., Nappi, F., Mastroianni, C., Giacinto, O., Pugliese, G., Casacalenda, A., Barbato, R., Barberi, F, Greco, S.M., Satriano, U., Forte, F., Miano, N., Colicchia, C., Di Lorenzo, D., Gaudino, M. and Chello, M. (2019) Preoperative Atorvastatin Reduces Bleeding and Blood Transfusions in Patients 
Undergoing Elective Isolated Aortic Valve Replacement. Interactive CardioVascular and Thoracic Surgery, Online.

[2] Zhai, Q., Wang, Y., Yuan, Z., Zhang, R. and Tian, A. (2019) Effects of Platelet-Rich Plasmapheresis during Cardiovascular Surgery: A Meta-Analysis of Randomized Controlled Clinical Trials. Journal of Clinical Anesthesia, 56, 88-97. https://doi.org/10.1016/j.jclinane.2019.01.018

[3] Madhu Krishna, N.R., Nagaraja, P.S., Singh, N.G., Nanjappa, S.N., Kumar, K.N., Prabhakar, V. and Manjunatha, N. (2019) Evaluation of Risk Scores in Predicting Perioperative Blood Transfusions in Adult Cardiac Surgery. Annals of Cardiac Anaesthesia, 22, 73-78. https://doi.org/10.4103/aca.ACA_18_18

[4] Martin, A., Chestovich, P.J., Lee, G.H., Ingalls, N.K. and Saldanha, V. (2016) Patients with Multiple Traumatic Amputations: An Analysis of Operation Enduring Freedom Joint Theatre Trauma Registry Data. Injury, 48, 75-79.

[5] Long, B. and Koyfman, A. (2016) Red Blood Cell Transfusion in the Emergency Department. The Journal of Emergency Medicine, 51, 120-130.

https://doi.org/10.1016/j.jemermed.2016.04.010

[6] Osvaldo, C. and Stefania, C. (2009) Protocolo para atendimento intra-hospitalar do trauma grave. Elsevier, Rio de Janeiro.

[7] Steinmetz, J., Marie, A.S., Henriksen, H.H., Lange, T., Larsen, C.F., Johansson, P.I. and Stensballe, J. (2016) Pilot Randomized Trial of Fibrinogen in Trauma Haemorrhage (Proof-Ith): Study Protocol for a Randomized Controlled Trial. Trials, 17, 327. https://doi.org/10.1186/s13063-016-1439-5

[8] Amatto, M. and Acharya, H. (2016) Secondary Hemochromatosis as a Result of Acute Transfusion-Induced Iron Overload in a Burn Patient. Burns \& Trauma, 4, 10. https://doi.org/10.1186/s41038-016-0034-Z

[9] Kanezaki, S., Miyazaki, M., Notani, N. and Tsumura, H. (2016) Clinical Presentation of Geriatric Polytrauma Patients with Severe Pelvic Fractures: Comparison with Younger Adult Patients. European Journal of Orthopaedic Surgery \& Traumatology, 26, 1822-1827. https://doi.org/10.1007/s00590-016-1822-7

[10] Jones, A.R. and Frazier, S.K. (2016) Association of Blood Component Ratio with Clinical Outcomes in Patients after Trauma and Massive Transfusion: A Systematic Review. Advanced Emergency Nursing Journal, 38, 157-168. https://doi.org/10.1097/TME.0000000000000103

[11] Stanković, B. and Stojanović, G. (2016) Chemotherapy Analysis in Massive Transfusion Syndrome. Medicinski Pregled, 69, 37-43. https://doi.org/10.2298/MPNS1602037S

[12] Holcomb, J.B., et al. (2015) Transfusão de Plasma, plaquetas e concentrado de hemáciasnarazão de 1:1:1 x 1:1:2 e mortalidadenospacientes com trauma severo: Estudo PROPPR (Transfusion of Plasma, Platelets, and Red Blood Cells in a 1:1:1 vs. a 1:1:2 Ratio and Mortality in Patients with Severe Trauma: The PROPPR Randomized Clinical Trial). JAMA, 313, 471-482.

https://doi.org/10.1001/jama.2015.12

[13] Benfield, R.J., Mamczak, C.N., Vo, K.T., Smith, T., Osborne, L., Sheppard, F.R., et al. (2012) Initial Predictors Associated with Outcome in Injured Multiple Traumatic Limb Amputations: A Kandahar-Based Combat Hospital Experience. Injury, 43, 1753-1758. https://doi.org/10.1016/j.injury.2012.06.030

[14] Jansen, J.O., Tai, N.R.M., Russell, R., Morrison, J. and Clasper, J. (2012) Midwinter M: Early Management of Proximal Traumatic Lower Extremity Amputation and Pelvic Injury Caused by Improvised Explosive Devices (IEDs). Injury, 43, 976-979. 
https://doi.org/10.1016/j.injury.2011.08.027

[15] Fleming, M., Waterman, S., Dunne, J., D’Alleyrand, J.C. and Anderson, R. (2011) Dismounted Complex Blast Injuries: Patterns of Injuries and Resource Utilization Associated with the Multiple Extremity Amputee. Journal of Surgical Orthopaedic Advances, 21, 32-37.

[16] Jacobs, N., Rourke, K., Rutherford, J., Hicks, A., Smith, S.R.C., Templeton, P., et al. (2014) Lower Limb Injuries Caused by Improvised Explosive Devices: Proposed Bastion Classification and Prospective Validation. Injury, 45, 1422-1428. https://doi.org/10.1016/j.injury.2012.05.001

[17] Ramasamy, A., Harrisson, S.E., Clasper, J.C. and Stewart, M.P.M. (2008) Injuries from Roadside Improvised Explosive Devices. Journal of Trauma Injury Infection and Critical Care, 65, 910-914. https://doi.org/10.1097/TA.0b013e3181848cf6

[18] Kreuger, C.A., Wenke, J.C. and Ficke, J.R. (2012) Ten Years at War: Comprehensive Analysis of Amputation Trends. Journal of Trauma and Acute Care Surgery, 73, S438-S43. https://doi.org/10.1097/TA.0b013e318275469c

[19] Hoencamp, R., Vermetten, E., Tan, E., Putter, H., Leene, L. and Hamming, J. (2014) Systematic Review of the Prevalence and Characteristics of Battle Casualties from NATO Coalition Forces in Iraq and Afghanistan. Injury, 45, 1028-1034. https://doi.org/10.1016/j.injury.2014.02.012

[20] Penn-Barwell, J.G., Bennett, P.M., Kay, A. and Sargeant, I.D. (2014) Acute Bilateral Leg Amputation Following Combat Injury in UK Servicemen. Injury, 45, 1105-1110. https://doi.org/10.1016/j.injury.2014.01.025

[21] Belmont, P.J., Goodma, G.P., Zacchilli, M., Posner, M., Evans, C. and Owens, B.D. (2010) Incidence and Epidemiology of Combat Injuries Sustained during the Surge Portion of Operation Iraqi Freedom by a US Army Brigade Combat Team. Journal of Trauma, 68, 204-210. https://doi.org/10.1097/TA.0b013e3181bdcf95

[22] Petersen, K., Cannegieter, S.C., Van Der Reijden, T.J., Van Strijen, B., You, D.M., Babel, B.S., et al. (2011) Diversity and Clinical Impact of Acinetobacterbaumanni Colonization and Infection at a Military Medical Center. Journal of Clinical Microbiology, 49, 159-166. https://doi.org/10.1128/JCM.00766-10

[23] Davis, K.A., Moran, K.A., McAllister, C.K. and Gray, P.J. (2005) Multidrug-Resistant Acinetobacter Extremity Infections in Soldiers. Emerging Infectious Diseases, 11, 1218-1224. https://doi.org/10.3201/1108.050103

[24] Podoll, A.S., Kozar, R., Holcomb, J.B. and Finkel, K.W. (2013) Incidence and Outcome of Early Acute Kidney Injury in Critically-Ill Trauma Patients. PLoS ONE, 8 , e77376. https://doi.org/10.1371/journal.pone.0077376

[25] Belmont, P.J., Schoenfeld, A.J. and Goodman, G. (2010) Epidemiology of Combat Wounds in Operation Iraqi Freedom and Operation Enduring Freedom: Orthopedic Burden of Disease. Journal of Surgical Orthopaedic Advances, 19, 2-7. 